\title{
Konzumeristički kapitalizam: epoha produkcije imaginarija potrošačke želje
}

\author{
Hajrudin Hromadžić \\ Filozofski fakultet u Rijeci, Odsjek za kulturalne studije, Rijeka, Hrvatska \\ e-mail: hhromadzic@ffri.hr
}

\begin{abstract}
SAŽETAK U tekstu se problematizira karakter epohe konzumerističkoga kapitalizma iz perspektive produkcije imaginarija potrošačke želje. Spomenuti se problem nastoji sagledati ne samo kao puki sociološko-kulturološki fenomen, već i ideološki, te se kao takav smješta u povijesni kontekst, u vremenski period koji započinje s 20-im godinama 20. stoljeća, prvo u SAD-u, a potom i u ostatku tzv. zapadnih kultura. Aspekti koji se ispostavljaju kao ključni u pokušaju interpretacije ishodišnoga fenomena jesu polje psihoanalize, pitanje odnosa neokapitalizma/neoliberalizma, ideologije socijalizma i potrošačke kulture, kao i značaj marketinško-oglašivačke mašinerije u kreiranju konzumerističkih fantazmi.
\end{abstract}

Ključne riječi: konzumeristički kapitalizam, potrošačka želja, marketing, oglašavanje.

\section{Uvodne smjernice}

Raspravljati o fenomenološkoj naravi konzumerizma, što je šira intencija ovoga rada, nužno znači (inter)disciplinarno ukrstiti niz područja, poput povijesti, psihologije, sociologije, ekonomije, politologije, antropologije, filozofije... Slijedom navedenoga, dva su temeljna problemska pristupa koja adresiraju tako široko postavljenoj uvodnoj matrici. Prvi možemo nazvati institucionalnim, a tiče se cijeloga niza strukturalno definiranih i promoviranih potrošačkih praksi, te je kao takav primarni motiv proučavanja sociološkoga, antropološkoga, povijesnoga, kao i političkogospodarskoga tipa. U drugom pristupu do izražaja dolaze prioriteti izučavanja konzumerizma kao seta osobnih interesa, orijentacija i svjetonazora, personalnih motivacija, dakle individualna razina, čime u prvi plan dospijevaju tematiziranja potrošačke kulture iz rakursa psihologije.

U užem smislu, tekst će problematizirati pitanje ideološke produkcije imaginarija potrošačke želje, te će tako definiran problemski motiv sagledavati kroz dihotomnu prizmu: duga povijesna tradicija promocije kulture "svrhovitih ljudskih potreba" nasuprot principu "demokratizacije potrošačke želje" unutar suvremenoga kapitalističkog sustava. S naglaskom na pokušaju interpretacije ideološko-manipulativne naravi, u ključnoj mjeri potrošačkom kulturom definiranoga, kapitalizma cijeloga 20. i ranoga 21. stoljeća, pokušat će se izbjeći mogućnost neproduktivnoga zastranjenja 
u ovakvom tipu rasprave. Primjerice, zapadanje u slijepu ulicu, oličeno u prividno vječitoj dilemi: u kojoj mjeri složena institucionalna aparatura uzrokuje nastanak potrošačke želje, a u kojem opsegu individualna potrošačka želja prethodi tržišnomarketinško-oglašivačkom zavođenju?

Nekoliko je radova koji pružaju uporabne putokaze za proučavanje ovoga fenomena. Jedan od njih je tekst baziran na komparativnom empirijskom istraživanju triju kultura (SAD, Turska, Danska), s ciljem fenomenološkoga uvida u koncept potrošačke želje, kojega potpisuju Belk, Ger i Askegaard. Navedeni autori detektiraju vernakularnu povezanost između potreba, htijenja i želja, počevši s tezom da je "potrošačka želja strast rođena između potrošačkih fantazija i društveno situacijskih konteksta” (Belk, Ger, Askegaard, 2003.:327), uz zaključak kako se potrošačka želja odnosi na moćan emocionalni ciklizam koji je kako neugodan, tako i prijatan. Klasičnu antropološku studiju na temu stvaranja kulture srednje klase u novom potrošačkom društvu s kraja osamdesetih i početka devedesetih godina 20. stoljeća, izvedenu na primjeru etnografskoga istraživanja u Katmanduu (Nepal), potpisuje Mark Liechty. Autor uočava kako dolazi do međuodnosa između novih formi globalno medijatiziranih potrošačkih želja i postojećih lokalnih, specifično tradicionalnih vrijednosti koje kreiraju rigidnu moralnu ekonomiju. Liechty je ovim istraživanjem ${ }^{1}$ uspio detektirati i dokumentirati period u kojem potrošačka želja još uvijek nije postala "prirodna komponenta imaginacije" (Liechty, 2003.:96), ali je izvjesno započeo proces njezine naturalizacije. Iako pisana iz drugačijeg vrijednosnoprosudbenoga rakursa, navedenim je tekstovima dijelom srodna analiza Clifforda Schultza. Članak je posvećen gospodarskom stanju u Vijetnamu u prvoj polovici 90-ih godina prošloga stoljeća, te s tim povezanim promjenama, autor ih čak naziva i revolucijama, na polju potrošačke kulture ovoga društva. Prema Schultzu, rapidno rasteći trend razvoja potrošačke kulture u Vijetnamu, usprkos brojnim preprekama poput krute birokracije, korupcije i nerazvijene infrastrukture, uz adekvatan korporativni odgovor glavni je faktor moderne vijetnamske renesanse (Schultz, 1994.).

Temeljna tendencija ovoga teksta je da se preko koncepta konzumerističke želje kompleksnije teorijski promisli složen odnos produkcije, to jest proizvodnje na jednoj, i potrošnje, odnosno konzumerizma, na drugoj strani, sve unutar suvremenoga kapitalističkoga sustava. Pritom zagovaramo tezu da postoje utemeljene pretpostavke kako bismo naše vrijeme mogli imenovati ne samo epohom neoliberalnoga, već i konzumerističkoga kapitalizma. U pokušaju kritičke valorizacije karaktera konzumerističkoga kapitalizma i ideologije produkcije, te promocije kulture potrošačke želje, osvrnut ćemo se i na razdoblje socijalizma. Ukazat ćemo na neke klasične teze neomarksističkoga tipa, kao i na nešto aktualnije teorije koje neomarksističko naslijeđe produktivno povezuju sa strukturalističkim i semiotičkim konceptima. Neizbježno je i pitanje uloge reklame, odnosno marketinškooglašivačkih strategija, u poticanju i kreiranju konzumerističkih želja.

1 Važno je i napomenuti kako je ovo istraživanje, u terenskom smislu, izvedeno krajem 80-ih i početkom 90-ih godina 20. stoljeća, dakle gotovo petnaest godina prije objavljivanja knjige. Taj podatak postane posebice indikativan u kontekstu brzoga ritma promjena karakteristika fenomena kakav je fenomen tzv. tranzicije u razvijenu, suvremenu potrošačku kulturu. 


\section{Povijesni kontekst nastanka konzumerističkoga kapitalizma}

U najkraćem, konzumeristički bi se kapitalizam mogao definirati kao epoha u kojoj "sama potrošnja postaje glavnim fokusom društvenoga života" (Čolić, 2008.:958). No, svakako nam je potrebna šira kontekstualizacija ovoga fenomena koja bi analitički interpretativno ukazala na povezanost doktrine neoliberalizma, tzv. postindustrijskoga kapitalizma i postmodernizma. Takvo mapiranje upućuje na početke 80-ih godina 20. stoljeća kao povijesne epizode "jednoga od najjačih ponovnih otkrića konzumerizma" (Slater, 1997.:10). U toj se epohi naime jasno isprepliću političke konture neoliberalizma² (posebice kroz tzv. tačerizam i reganizam), gospodarske odlike tzv. postindustrijalizma (kognitivni kapitalizam, dominacija informacijskokomunikacijskih i servisno-uslužnih djelatnosti, prekarni rad, fleksibilna akumulacija kapitala...), socijalne karakteristike sve izrazitijega individualizma i kulturalne dimenzije postmodernizma (masmedijski potpomognuta spektakularizacija i estetizacija svakodnevice, trijumf znaka i logike označavanja, visoko razvijena reklamna industrija, profesionalizacija marketinga i oglašavanja), koje nalaze svoje uporište u novom tipu potrošačke kulture - ideologiji konzumerističkoga kapitalizma kao društveno-kulturalnoj dimenziji gospodarsko-političke matrice neoliberalizma 3 .

Ono što je karakteristika ovako trasiranoga pristupa jest da potrošačku kulturu svjesno reducira na kontekst naslijeđa recentnije povijesti zapadnih država, odnosno industrijske kapitalističke revolucije, tržišno-relacijskih odnosa i kulturalnih

2

2 Danas sveprisutan i (pre)često apliciran termin-koncept neoliberalizam doživljava svoju (re) afirmaciju u 70-im i 80-im godinama 20. stoljeća, premda povijesno-razvojna geneza ideje neoliberalizma, koji nije samo ekonomski, već i društveno-ideološki model, seže do 30-ih godina prošloga stoljeća. Neoliberalizam počiva na tri temeljna načela kojima je zajednička ideja o "slaboj državi": zakonsko-legislativna deregulacija (u svrhu otklanjanja administrativno--birokratskih prepreka i posljedičnom olakšavanju poduzetničko-tržišnih inicijativa), sveopća privatizacija (ne samo državno-društvenih proizvodno-industrijskih kapaciteta, već i usluga od javnoga značaja, poput obrazovanja i zdravstva, te prirodnih dobara, kao što su vode i šume...) i maksimalno rezanje svih javnih rashoda. Centralni akteri u realizaciji ovoga modela globalne megakorporacije velike su investicijsko-špekulativne banke, kreditne agencije i transnacionalne institucije poput Međunarodnoga monetarnog fonda i Svjetske trgovinske organizacije. U ideološkom smislu, radi se o "teoriji političko-ideoloških praksi koje predlažu da ljudski prosperitet može biti unaprijeđen liberalizacijom individualnih poduzetničkih sloboda i vještina unutar institucionalnog okvira kojeg karakteriziraju privatna vlasnička prava, sloboda tržišta i slobodna trgovina" (Harvey, 2005.:2). Neki autori ispravno ukazuju da "glavno obilježje toga novoga, radikalnoga modela kapitalizma jest zaokret prema maksimizaciji profita po svaku cijenu, osobito snižavanjem troškova rada" (Mesarić, 2006.:612).

3 Unutar ovako skiciranoga modela treba tražiti povijesne izvode transformacija optočenih konzumerističkom aurom s kojima se i mi, u našim lokalnim, tzv. tranzicijskim (neokolonijalnim) kontekstima danas suočavamo i čemu živo svjedočimo: transformacije identiteta iz građanina u potrošača, pretvorbe javnih prostora od društvenoga značaja (ulice, trgovi, parkovi) u privatne prostore za oplodnju kapitala i dosezanje profita (tržišni centri i parkinzi), penetracija oglasnih panoa i reklamnih billboarda u sve kutke ljudskoga vidokruga (unutar društvenih okoliša, ali i prirodnih pejzaža), nakaradne situacije u kojima sama potrošnja postaje svojevrsna proizvodnja, itd., itd. 
karakteristika zapadnih društava. Naime, već je postalo općim mjestom u raspravama na ove teme osvrnuti se na klasičnu Campbellovu studiju o romantičnoj etici i duhu suvremenoga konzumerizma, u kojoj su počeci moderne potrošačke kulture vremenski smješteni u zadnja desetljeća 18. stoljeća, u vrijeme tzv. romantizma, već prema dobro poznatoj teoriji u kojoj romantična etika ranoga modernizma predstavlja konzumerističko-hedonistički, povijesno-usporedni pandan weberijanskoj protestantskoj radnoj etici ranoga industrijskog kapitalizma (Campbell, 1987.). Niz teoretičara ide i korak dalje, te upozorava kako je očite znakove konzumerističkih sindroma i potrošačkog lifestyla moguće pronaći puno prije kraja 18. stoljeća, kroz primjere srednjovjekovne aristokracije ili u nizu europskih feudalaca u dugom rasponu od 5. do 12. stoljeća (Stearns, 2001.:1-2), kao i još dalje u povijest prema staroj Grčkoj i starome Rimu. Također, takvi pristupi, premda ne negiraju tezu kako je Zapad kolijevka moderne potrošačke kulture, naglašavaju i da se, barem od kraja 19. stoljeća nadalje, kultura konzumerizma širi kao globalni planetarni fenomen ne ostavljajući gotovo ni jedan kutak svijeta netaknutim. No, za Campbella je povijesna epoha romantizma od presudnog značaja jer se prema njegovim uvidima upravo tada pojavljuju dotad nepoznate manifestacije fenomena čežnje, maštanja, sanjarenja, traganja, fantaziranja, usmjerene prema novom, još neiskustvenom, nepoznatom predmetu želje.

Za nas je pak u ovom tekstu od centralnoga značaja vremenski period s kraja 19. i početka 20. stoljeća, koji kulminira u 20-im godinama 20. stoljeća, razdoblje u kojem se kristaliziraju jasni počeci već spomenute produkcije potrošačkoga imaginarija želje. Taj ćemo fenomen u nastavku teksta tretirati kao ključni za definiranje karaktera konzumerističkoga kapitalizma. Objašnjavajući važnost ovoga povijesnog perioda u kontekstu rađanja moderne potrošačke kulture, Slater naglašava nekoliko međusobno povezanih razvojnih faktora koji su na to utjecali: masovnu potrošnju, geografsko i društveno širenje tržišta, racionalizaciju oblika i organizacije produkcije (Slater, 1997.:13). Isti autor smatra kako su 20-te godine prošloga stoljeća bile vjerojatno prvo povijesno desetljeće koje je proklamiralo ideologiju obilja i bogatstva, zaključujući da je "od 1920-ih svijet dijelom bio moderniziran kroz konzumpciju; sama potrošačka kultura bila je podložna ideji da svakodnevni život može i treba biti moderan..." (Slater, 1997.:12). Radi se, dakle, o epohi u kojoj "konzumpcija i bivanje potrošačem više nisu opcije. To su neizbježne aktivnosti i identiteti onih koji žive u eri zreloga potrošačkog kapitalizma (približno od 1920-ih naovamo) " (Cook, 2005.:163). Također, nije nevažan podatak kako upravo u ovom desetljeću američke banke započinju s poslovnom politikom odobravanja potrošačkih kredita s otplatom na obroke.

Prema uvidima Susan J. Matt, legitimizacija društvenoga statusa potrošačke želje predstavljala je jedan od važnih faktora nadomještanja ispražnjene viktorijanske kulture, obilježene, između ostaloga, i protestantskom etikom kulture umjerenosti i potrošačke skromnosti - s ranim trendovima moderne kulture u razdoblju između 1890. i 1930.

U ovom periodu, paralelno s društveno-gospodarskim procesima, uznapredovale industrijalizacije, uzleta masovne tržišne maloprodaje i prvih naznaka popularne 
kulture, dogodio se presudan emocionalni preokret kod velikoga broja Amerikanaca: želja za posjedovanjem potrošačkih objekata i njihovom konzumacijom nije više shvaćena kao nemoralan grijeh već kao pozitivna stvar (Matt, 2003.). Analizom djela Porgy američkoga autora DuBose Heywarda, prvi put objavljenoga 1925., kojeg smatra egzemplarnim primjerom tzv. negrotarian ${ }^{4}$ romana, Chip Rhodes na konkretnom primjeru pokazuje povijesni tijek konstrukcije konzumerističke želje u SAD-u u 20-im godinama prošloga stoljeća. Teza ovoga autora je kako promicanjem ovakve ideologije, koja naravno nema antagonističke pretenzije spram korporativnoga kapitalizma - "ljudska esencija pronalazi ekspresiju bilo gdje unutar potrošačkog tržišta" (Rhodes, 1994.:193).

\section{Potrošački imaginarij želje}

Kako bismo potpunije razumjeli naznačeni problemski motiv, važno je, barem u osnovnim naznakama, napraviti iskorak k anatomiji koncepta želje iz psihoanalitičke perspektive. Drugim riječima, potrebno se vratiti ishodištima - tezama Sigmunda Freuda. U najkraćem, Freud koncept želje (Wunsch) razumije kao čežnju za fundamentalno izgubljenim objektom i svaka potraga za njim jest pokušaj obnove izgubljenoga jedinstva. Želja je pozicionirana unutar $i d a$, jedne od tri razine u konstituciji ličnosti prema Freudu (ostale dvije razine su ego i superego). Id je sastavljen od bazičnih, primordijalnih ljudskih impulsa koji zahtijevaju permanentno zadovoljenje, satisfakciju ${ }^{5}$. Mjesto realizacije želje jesu snovi, navodi Freud u uvodnim stranicama znamenite Interpretacije snova, odnosno snovi su zamaskirano ispunjenje nesvjesne želje. U tom primjeru svjedočimo dvostrukoj ulozi želje jer je po jednoj strani sadržaj sna ispunjenje želje, ali je i motiv samoga sna također želja. Freud koristi snove kako bi derivirao svoju bazičnu topografiju, odnosno model psihičkoga aparata koji definira želju kao cathexis (što označava koncentraciju emocionalne energije na objekt ili ideju) - memorijske slike povezane sa zadovoljenjem potrebe. Pritom je, prema Freudu, želju moguće zadovoljiti samo jednom i svaka naknadna manifestacija želje jest samo impuls kojim se nastoji ponovno uspostaviti slika nenadoknadivoga objekta (Freud, 1997.).

Kasnije će Lacan dijelom reinterpretirati Freudov koncept želje na način da će ponuditi tezu prema kojoj objekt želje prethodi samoj želji i figurira kao njezin uzročnik (Lacan, 1966./2005.). Zapravo, Lacanovo razumijevanje objekta želje korelira s psihoanalitičkim konceptom das Ding. Riječ je o Stvari koja je izvorna praznina, rupa u strukturi oko koje se strukturira želja. Jasno nam je kako objekt želje nikada ne može zadovoljiti samu želju subjekta (potrošača), želja uvijek pronalazi nove objekte svoje fascinacije, tako da je imaginarni krug željâ vječno perpetuirajući, njega nikada nije moguće zatvoriti, zaključiti. Iz ove, psihoanalitičko-poststrukturalističke

\footnotetext{
${ }^{4}$ Terminom negrotarians označavani su bijelci koji su podupirali crne umjetnike.

5 Prevedeni u diskurs potrošačke kulture, primordijalni impulsi smješteni u sferu ida manifestirali bi se u tako običnim, zdravorazumsko-svakodnevnim artikulacijama želje: novi automobil ili stan, seksualne fantazije, posao iz snova...
} 
perspektive, potrošačke prakse simbolički reprezentiraju manifestaciju dijela ljudske podsvijesti i funkcioniraju kroz diskurs želje. Pritom je rasprava o diskursu želje, ovdje aplicirana na primjer konzumerizma, iz perspektive Foucaultove teorije još kompleksnija "jer diskurs... nije tek ono što izražava borbe i sisteme vladavine, već ono zbog čega i pomoću čega se vodi borba, moć koje se valja dočepati... jer diskurs - kao što je pokazala psihoanaliza - nije tek ono što očituje (ili skriva) želju; on je i predmet želje" (Foucault, 1994.:117).

Što je u naslijeđu psihoanalitičkoga (prije svega Freudovoga, ali i Lacanovoga) učenja od ključnoga značaja po pitanju logike funkcioniranja suvremene potrošačke matrice? Naime, sve do 20-ih godina 20. stoljeća konzumerizam je još uvijek bio percipiran u sferi "svrhovitoga konzumerizma", kao napor u cilju zadovoljenja bioloških i socijalnih potreba, a "kada su potrebe jednom ostvarene (kada su 'potrebe' jednom 'zadovoljene'), više nije bilo potrebe za daljnjom konzumacijom” (Bauman, 2002.:181). Promatrajući ovaj fenomen iz perspektive definiranja karaktera zreloga buržoaskoga društva kojem je i sam Freud pripadao i u kojem je živio, "želje su psihološke, a ne biološke, i po svojoj su naravi neograničene" (Bell prema Čolić, 2008.:956). Nadalje, za suvremeni konzumerizam ranoga 20. stoljeća vrlo važnim postaje aspekt "konzumiranja konzumerističke želje" (Bauman, 2002.:184), kao i "osobitost moderne tržišne ekonomije" čiji "motivi za stjecanje dobara nisu potrebe nego želje, koje su po svojoj naravi neograničene i nezasitne" (Čolić, 2008.:957). Ili, ponovimo to u diskursu psihoanalize, "želja ne želi zadovoljenje. Suprotno, želja želi želju” (Taylor i Saarinen prema Beilharz, 2001.:314). Posljedično, u okvirima predočene paradigme želje koja se razvija gotovo cijelim tijekom 20. i ranoga 21. stoljeća, trasirana je putanja transformacije iz društva proizvođača u društvo potrošača u okvirima nadolazećega fenomena, kojeg Bauman imenuje tekućom modernošću. U obličju novoga tipa konzumerističkoga društva kasne moderne, pojedinci simultano postaju promotori roba, ali i sama roba koju promoviraju. Svjedočimo zapravo "transformaciji potrošača u robu", odnosno "fetišizmu subjektiviteta" (Bauman, 2007.:12-14).

Radi se, dakle, o svojevrsnom zatvorenom krugu neprestane, sve ubrzanije ideološke produkcije konzumerističkih želja, koje se hrane trajnim potrošačkim nezadovoljstvom, neispunjenjem. Yves Charles Zarka, tematizirajući tri antropološka temelja kapitalizma, piše o gotovo istovjetnim problemima kada naglašava aspekte koje naziva dinamikom žudnje (mehanizam aktiviranja, stimuliranja i pojačavanja individualne žudnje), te posebice homogenizacijom objekta žudnje (težnja za materijalnim satisfakcijama putem akumulacije predmeta). Razina homogenizacije objekta žudnje, prema mišljenju ovoga autora, upravo je u domeni potrošačke kulture, odnosno "karakter žudnje objašnjava jednu od glavnih dimenzija kapitalizma, koji se ne može održati drugačije do ekspanzijom i obnavljanjem predmeta potrošnje" (Zarka, 2010.:23). Žižek, raspravljajući o fenomenologiji želje u ponešto drukčijem kontekstu problema nasilja i tendencije za posjedovanjem moći, a pozivajući se pritom na francusku religijsku teoretičarku Simone Weil, tvrdi kako "želja zahtijeva sve više nego što je potrebno", te da je pravi izazov "zadržati i sačuvati prikladnu mjeru želje" (Žižek, 2008.:57). Izlaz je, smatra Weil, a s njom se slaže i Žižek, u tome da svaki pojedinac postavi granicu vlastitim željama, pri čemu postoji jasna distinkcija 
između "ograničenih želja koje su u harmoničnom odnosu spram želja, a želje koje teže bezgraničnom to nisu” (Weil prema Žižek, 2008.:57).

Već ranije nakratko spomenutu puritansku protestantsku etiku koja dominira na zapadu sve do kraja 19. i početka 20. stoljeća, polako ali sigurno u sve većoj mjeri nadomješta materijalistički hedonizam, to jest ono što Daniel Bell imenuje psihološkim eudaimonizmom (od grčke riječi eudaimonia, što znači sreća, blaženstvo). Radi se o teoriji prema kojoj su sreća i ugodnost krajnji ciljevi ljudskoga života (Čolić, 2008.:955, 967). Dakle, ulazak u epohu konzumerističkoga kapitalizma označio je i raskid s relativno dugom tradicijom dominacije kulture zadovoljenja svrhovitih potreba. Time suvremeni hedonizam konzumerističkoga kapitalizma "karakterizira preokupacija 'uživanjem', koje je zamišljeno kao potencijalna kvaliteta svakoga iskustva” (Čolić, 2008.: 957). Širenjem masovnoga tržišta i omasovljenjem potrošačke kulture nakon 2. svjetskoga rata, te posebice artikulacijom niza popularno kulturnih društvenih obrazaca od 60-ih godina 20. stoljeća, spomenuti fenomeni započinju naprosto prožimati svakodnevicu, te postaju dio problemskih motiva sve brojnijih teorijskih i istraživačkih proučavanja.

Primjerice, tzv. francuski situacionisti (pokret Situacionistička Internacionala ${ }^{6}$ ) u 60im godinama 20. stoljeća govore o procesima društvene konstrukcije pseudopotreba. Posebice se to odnosi na prominentan koncept društva spektakla Guyja Deborda. Kada ekonomija dominira cjelokupnim društvenim životom, spektakularno producirane pseudopotrebe posljedično zamjenjuju autentične ljudske potrebe, piše Debord u svojoj knjizi Društvo spektakla. Konstrukcija pseudopotreba u nadležnosti je masovnih medija i oglašivačkih agencija koje produciraju beskrajne serije zavodljivih reklamnih slika za masovnu konzumpciju. "Selebritiji" sa svih područja, filma, muzike, sporta, čak i znanosti, postaju virtualno utjelovljenje fantazmagorične egzistencije spektakla. Posljedično, svakodnevni život dospijeva pod invaziju kulture spektakla, tako da postaje sve teže razlikovati realnost od uprizorenja spektakularnoga (Debord, 1967/1999.). Otprilike u isto vrijeme kada su i situacionisti bili aktivni, jedan od pripadnika tzv. Frankfurtske škole kritičke teorije društva ${ }^{7}$, Leo

6 Najprominentniji članovi Situacionističke Internacionale (SI) bili su Guy Debord, Raoul Vaneigem, Michele Bernstein i Alexander Trocchi. SI je službeno egzistirala između 1957. i 1972. u Parizu. "Situacionisti" su predstavljali jednu od centralnih i vodećih snaga u pokretanju socijalnih i kulturnih događanja iz svibnja i lipnja ‘68., a svoju su kritiku društva koncipirali kroz spoj inspiracije s projektima avangardističkih umjetničkih pravaca (prije svega dadaizma i nadrealizma) i utjecaja intelektualnih teza lijevo orijentiranih političkih filozofija (prije svih Marxa, Lukácsa i Lefebvrea), pri čemu su i sami bili nadahnuće nekim kasnijim alternativnokulturnim gibanjima i aktivističkim pokretima.

7 Misli se na skupinu prominentnih njemačkih filozofa i sociologa poput Adorna, Marcusea, Horkheimera i Benjamina, okupljenim oko Instituta za socijalna istraživanja, koji je osnovan 1923. Činjenica da se radilo o intelektualcima židovskoga podrijetla neomarksističke provenijencije, rezultirala je preseljenjem Instituta iz Frankfurta u New York odmah nakon dolaska nacionalsocijalista na vlast u Njemačkoj 1933. U SAD-u su "frankfurtovci" izgradili sustavan teorijski korpus posvećen kritici kapitalizma, masovnoj kulturnoj industriji, ranom potrošačkom društvu i produkciji svijeta kroz matricu masovnih medija. Nakon završetka 2. svjetskog rata, Institut se 1949. ponovno vratio u Frankfurt. 
Lowenthal, objavljuje zanimljivu studiju posvećenu povijesnoj analizi uloge i mjesta masovnih medija u produkciji i reprodukciji "slavnih". Slijedeći Lowenthalovim tezama, dvadesete godine 20. stoljeća donose zanimljiv obrat u medijskoj percepciji i konstrukciji celebrity kulture. Lowenthal naime primjećuje da su prije toga perioda na stranicama popularnih američkih magazina s kraja 19. i početka 20. stoljeća, dominirale tzv. "produkcijske ikone" koje su predstavljali menadžeri, bankari, tj. uspješni poslovni ljudi. Treće desetljeće prošloga stoljeća uvodi promjenu na način da "produkcijske ikone" zamjenjuju tzv. "konzumerističke ikone", sastavljene od glumaca, muzičara, sportaša i sličnih aktera rane popularne kulture (Lowenthal, 1961.).

\section{Ideološka potka konzumerističke želje}

Kako odgovoriti opisanim izazovima konzumerističkoga kapitalizma i ideologiji produkcije i promocije kulture potrošačke želje? Za potencijalne putokaze u pokušaju odgovora na postavljeno pitanje potrebno je napraviti iskorak k ideološko-antagonističkim, klasnim i gospodarskim okolnostima materijalnih uvjeta proizvodnje konzumerističkoga koncepta želje. Riječ je, dakle, o prostoru političke ekonomije, mjestu na kojem se konture potrošačke kulture direktno povezuju s određenim ideološko--sistemskim modelima. Sva se dosadašnja rasprava o ovim fenomenima u tekstu vodila iz perspektive (neoliberalnoga) kapitalizma i njegovih hegemonijskih učinaka po pitanju ideološkoga karaktera konzumerizma i koncepta potrošačke želje. No, itekako se smisleno zapitati i o odnosu potrošačke kulture i ideologije socijalizma. Nemali broj teoretičara iznosi sumnju uopće u mogućnost da se govori o postojanju konzumerizma u socijalističkim društvima. Kako to kritički primjećuje Duda, radi se o teorijama i autorima koji "potrošačko društvo povezuju samo sa zapadnim kapitalističkim uređenjima”, a iz teze o navodnom nepostojanju potrošačke kulture u socijalističkim državama izvlače dalekosežne i pomalo ishitrene zaključke kako je to i "glavni razlog propasti socijalističkih režima krajem 80-ih" (Duda, 2005.:57).

No, stvari baš i nisu tako jednostavno svedive na binarno-simplifikacijsku razinu problema. Činjenica jest da su socijalistički režimi često koristili odlike potrošačke kulture kao primjere u svrhu ideološko-propagandne borbe protiv kapitalističkoga uređenja. Iz te su se perspektive manifestacije potrošačke kulture interpretirale kao simptomi zapadno-kapitalističke dekadencije, nasuprot čemu su se nalazila glorificirana načela navodne moralne superiornosti radničke klase, oslikane i kroz tzv. racionalnu potrošnju, svedivu na zadovoljavanje potreba, a ne na slijeđenje imaginarija konzumerističke želje (Hromadžić, 2008.:69-70). Kako to jasno zaključuje Stearns, "kao posljedica ideološkoga stava, komunistički su lideri kontinuirano napadali zapadni konzumerizam kao znak dekadencije i nejednakosti kapitalističkoga društva" (Stearns, 2001.:78). Ipak, postoji i druga strana priče. Naime, konzumerizam je itekako uspješno penetrirao i u društvenu svakodnevicu nekadašnjih socijalističkih društava, prije svega kroz dokoličarske prakse, primjerice poticanjem na odlaske na kolektivno organizirane godišnje odmore. Štoviše, Stearns u svojoj studiji navodi i primjere filmova iz Rusije već u 30-im godinama 20. stoljeća, koji su na neki način veličali konzumerizam, sve u cilju ideološke reinterpretacije konzumerizma koji je prema toj novoj narativnoj matrici trebao biti tretiran kao 
dio komunističkoga uspjeha (Stearns, 2001.:79-80). Stanić ide i korak dalje, u smislu povijesne periodizacije ovoga fenomena, kada analizira razliku između socijalizma, na primjeru jugoslavenskoga samoupravnog modela i kapitalističke liberalne demokracije, sve u kontekstu potrošačkih praksi provučenih kroz optiku tzv. tranzicije. Prema uvidima autorice, ključni faktori razlikovanja su društvene i gospodarske okolnosti, te društvena stratifikacija, pri čemu su prilike u socijalizmu "uvjetovale utilitarnu potrošnju, opterećenu oskudicama i nestašicama”, dok se tranzicijski kapitalizam "kroz opću demokratizaciju u potrošnji manifestira kao maksimalna dostupnost svega. Uz raspoloživost potrošačke ponude, pojavljuju se, međutim, i ograničenja punoga potrošačkog sudjelovanja, koja su determinirana osnovnim obilježjima novoga sustava i svojstvenom mu stratifikacijom" (Stanić, 2010.:278-279).

Još jedan važan aspekt potrošačke kulture kojega je važno artikulirati u kontekstu tematiziranja odnosa (post)socijalizma i konzumerizma jest koncept nostalgije. Niz je primjera koji ukazuju na činjenicu kako je konstrukt nostalgičnoga sjećanja na proteklu epohu, zemlju ili ličnost, u značajnoj mjeri i produkt konzumerističkih artefakata i potrošačkih praksi vremena kojega nostalgični narativ priziva i na kojega se poziva (Hromadžić, 2008.:77-78). U opsežnoj interpretaciji koncepta nostalgije, Velikonja, između ostaloga, zaključuje kako je kultura nostalgije promovirana i s pomoću "promućurnih 'trendsetera' masovne i potrošačke kulture" (Velikonja, 2010.:45). Pritom je posebice zanimljiv istočnonjemački primjer Ostaligie, termina kojim se označava nostalgija istočnih Nijemaca za nekadašnjim DDR-om. Prema Boyeru taj je fenomen više primjer projekcije i produkcije zapadnih Nijemaca o tome što u stvari nedostaje njihovim istočnim sugrađanima, te ga iz tih razloga zamjenjuje pojmom Westalgie (Boyer prema Velikonja, 2010.:45). Dodatno, važan interpretacijski zaokret donosi Cook govoreći o Ostalgie kao o emotivnoj povezanosti s nečim izgubljenim, što je za ovoga autora i nešto više, znak narušavanja logike konzumerističke potrošnje. "Kada je ovaj oblik odnosa k materijalnoj kulturi počeo bivati privlačnim zapadnim Nijemcima, zaprijetio je da ugrozi logiku potrošačke potražnje u kapitalističkom sustavu. Otkrio je ispraznost potrošačkoga izbora i objelodanio kako je proces konstantne produkcije inovacije utemeljen na kruženju želje za željom”, pronicljivo zaključuje Cook (Cook, 2007.:214).

Upravo nas posljednji citat o "ispraznosti potrošačkog izbora temeljenoga na neprestanoj cirkulaciji želje”, dovodi na trag pomalo zaboravljenih teza prominentnoga francuskoga filozofa neomarksističke provenijencije iz druge polovice 20. stoljeća, Henrija Lefebvrea. Lefebvre je kao učitelj i intelektualni autoritet imao veliki utjecaj na spomenute situacioniste, iako su se nerijetko i oštro sukobljavali ${ }^{8}$. Premda neoka-

8 Situacionisti su primjerice optužili Lefebvrea (koji je predavao sociologiju Debordu i Vaneigemu na sveučilištu Nanterre u akademskoj godini 1957./1958. i imao veliki utjecaj na oblikovanje ishodišne platforme Situacionističke Internacionale) da je ukrao njihovu analizu Pariške komune. Ipak, primjedbe situacionista njihovom učitelju bile su pomalo paradoksalne. Naime, upravo su situacionisti bili među prvima koji su promovirali ideju o neizbježnosti kulture plagijarizma u kontekstu progresa koji ga povlači sa sobom. 
pitalizam - termin kojeg Lefebvre koristi u gotovo sinonimnom značenju s onim što mi danas običavamo imenovati neoliberalizmom, teži postizanju apsolutno kontroliranoga konzumerizma, ne samo u smislu produkcije potrošačkih objekata i usluga, već i u vidu obećane satisfakcije putem njih, on ne može prodati sreću, ma koliko to tvrdio, smatra Lefebvre. Rezultat je opći osjećaj nelagode i nezadovoljenja, te potpune krize vrijednosti koja ne pokazuje znakove kraja unutar postojećega horizonta konzumerističkoga kapitalizma. Ahilovu petu neokapitalizma Lefebvre pronalazi u anomiji želje, njezinoj društveno-nedruštvenoj prirodi, opstojanju socijalne i intelektualne sistematizacije u nastojanju da reducira želju na distinktivnu, klasificiranu potrebu za zadovoljenjem. Da bi želja bila organizirana i sistematizirana, njezini označitelji moraju biti precizno označeni. Želja mora biti stimulirana znakovima, formama koje prizivaju želju. No, želja, prema njegovom mišljenju, odbija da bude označena jer ona sama kreira svoje vlastite znakove. Znakovi i simboli želje mogu jedino isprovocirati parodiju želje koja nije ništa više do izgovor za realnu stvar (Lefebvre, 1981./1988.). U definiranju prethodno spomenutih stavova na Lefebvrea su presudno utjecale teze svetoga Augustina, kojega je studirao u ranoj mladosti, dok je još uvijek bio duboko religiozan. Augustin definira bivstvovanje htijenjem (le vouloir) i željom (le désir), a ne znanjem. Lefebvre ukazuje na to da kod Augustina beskonačna želja, kada pada u konačno, postaje trostruki libido: libido sciendi, libido sentiedni i libido dominandi - a svaki je libido za Augustina tek sjena beskonačne želje (Kullashi, 1986.:13).

Kasniji će neomarksistički teoretičari - preuzevši niz koncepata (post)strukturalizma i strukturalne lingvistike pod okriljem postmodernističkih teorija, učiniti interpretacije konzumerizma i potrošačkoga kapitalizma još kompleksnijim. Primjerice Baudrillard, koji već s početka 70-ih godina 20. stoljeća iznosi teze prema kojima već odavno ne kupujemo samo neposredne proizvode u njihovoj uporabnoj, materijalnoj vrijednosti, već kupujemo znakove, simboličke reprezentacije koje virtualno egzistiraju na mjestu proizvedenoga materijalnog supstrata. Radi se o prijelazu iz uporabne u označiteljsku vrijednost, što predstavlja jasnu reaktualizaciju Marxovoga koncepta robnoga fetišizma s uvodnih stranica prvoga toma Kapitala, u spoju s de Saussureovim sustavom lingvističkoga strukturalizma. Nadalje, potrošački su artefakti tek vodilje u perpetuaciji neiscrpne imaginacije potrošačke želje. Želja za posjedovanjem određenoga proizvoda često je i više od njegove puke funkcionalnosti, a odabir proizvoda nosi u pozadini snažan identitetsko-reprezentativni i identifikacijski značaj za kupca, potrošača, kao i estetizacijski učinak. Baudrillard razvija svoje teze o potrošačkom društvu na način da potrošački predmeti interpretira kao "sustav znakova koji obavlja diferencijacijsku funkciju među ljudima” (Kalanj, 2001.:IX). Prepoznatljiva je Baudrillardova teza i kako potrošnja nije tek završna etapa procesa započetoga s proizvodnjom, već je konzumerizam i više od toga: to je sustav semiotičke razmjene koji ostvaruje značenja jednaka svakom drugom jeziku. Prema Baudrillardovom mišljenju, potrošačko društvo, utemeljeno na hiperprodukciji roba i usluga, a ne na oskudici, estetizira ili "kulturalizira" iskustva i vrijednosti. No, s obzirom da ne postoji objektivna potreba za tolikom paletom roba i usluga, impuls potrošačke želje mora biti aktivno i neprekidno stimuliran mehanizmima oglašavanja i marketinških strategija prodaje (Baudrillard, 1970.). 


\section{Marketinško-oglašivački stroj i njegovi učinci}

U Hrvatskoj je nedavno (travanj 2011.) dovršeno istraživanje studenata psihologije i medicine Sveučilišta u Osijeku, u kojem je ishodišno pitanje bilo zašto i kako u vremenu besparice i krize trošimo više od naših financijskih mogućnosti. U istraživanju se krenulo od lako uočljive premise kako trošimo ono čega nemamo (virtualni novac putem kreditnih kartica), na mjestima koja su upravo stvorena s nakanom da bi nešto takvo bilo moguće i ostvarivo (tržišni centri), a pritom osjećamo privremeno zadovoljstvo, čak oblik sreće. "Odem po jednu stvar, kupim deset, ali ne kupim ono po što sam krenula", izjavljuje u prilogu HTV-a jedna šopingholičarka, detektirajući time neuralgičnu točku ovisnosti o potrošnji. Televizijski prilog ${ }^{9}$ upozorava i na neke od ključnih detalja koji su dio prodajnih strategija u manipulacijama potrošačima, poput rasporeda pokretnih stepenica u tržnim centrima (morate napraviti cijeli polukrug da biste došli do sljedećih koje vas vode na viši kat, a pritom se susrećete s nizom izloga) ili činjenice da je najskuplja i najatraktivnija roba smještena s desne strane kojom se ljudi najčešće kreću i to u visini očiju, to jest pogleda. Zaključak do kojega se u istraživanju došlo ispostavlja tezu kako našim potrošačkim emocijama i sentimentima upravljaju i manipuliraju stručnjaci za neuromarketing ${ }^{10}$.

Nisu rijetka istraživanja koja se bave sve više prepoznatljivim pojavnostima "poremećaja prisilnoga kupovanja" upravo iz spomenute neurološke, medicinskopsihološke perspektive (za više o tome u Hromadžić, 2008.:89). U prethodnom poglavlju elaborirana teza kako potrošačke proizvode i usluge i dalje konzumiramo u domeni njihove praktično uporabne vrijednosti, ali da oni za nas istovremeno imaju i ogromnu simboličku, kulturalno-socijalno označiteljsku funkciju, upućuje nas na značaj industrije marketinškoga oglašavanja po ovom pitanju. Naime, s obzirom kako se ipak radi o sociološko-kulturološkim fenomenima, u raspravama na ove teme potrebno je uzeti u obzir cijeli niz ideološko-manipulativnih aspekata produkcije simptoma potrošačke želje, koji su primarno rukovođeni tržišnim motivima oplodnje kapitala i ostvarivanja profita. Oruđa za njihovu realizaciju u rukama su korporativnih stručnjaka za marketing i oglašavanje. Kako to pokazuje analiza Oropese o vezi između potrošačkoga vlasništva, potrošačkih strasti i subjektivne dobrobiti, tržišno-centristička perspektiva naglašava navodno pozitivne strane akumulacije različitih tipova potrošačkih dobara (Oropesa, 1995.). No, upravo je beskonačna akumulacija i gomilanje potrošačkih dobara čest razlog za, primjerice, svima nam dobro poznatu konfuziju u situacijama odabira produkata s beskonačno nanizanih polica u supermarketima ili trgovačkim centrima. Mogilner, Rudnick i Iyengar su svojim istraživanjem potvrdili tezu o "efektu puke kategorizacije" potrošačkih dobara, gdje su uspjeli pokazati kako su potrošači sretniji sa svojim izborom ukoliko su njihove opcije izbora kategorizirane, čak i ukoliko su takve kategorizacije ponekad besmislene (Mogilner, Rudnick, Iyengar, 2008.).

9 Riječ je o dvominutnom prilogu Hrvatske televizije, emitiranom na kraju centralne informativne emisije Dnevnik 2 u 19.30 h, 18. 04. 2011.

10 Radi se o interdisciplinarnoj znanstvenoj oblasti, staroj tek desetak godina, koja povezuje polja neurologije i marketinga s ciljem otkrivanja i objašnjenja podsvjesnih reakcija potrošača na marketinško-oglašivačke podražaje. Neuromarketing se primarno koristi od strane kompanija kako bi se povećala učinkovitost i produktivnost njihovih kampanja (Jureško, 2011.). 
O Edwardu Bernaysu, "ocu suvremenog PR-a" i njegovoj sposobnosti učinkovitoga povezivanja simbola potrošačke industrije s objašnjenim psihoanalitičkim konceptima njegova strica Sigmunda Freuda, te umijeću da te koncepte potom uspješno propagandno-oglašivački i marketinški aplicira na američko tržište od 20-ih godina prošloga stoljeća nadalje, već smo opsežno pisali na drugom mjestu (Hromadžić, 2008.:9-17). Bernaysu su bili bliski stavovi američkoga bankara Paula Mazura, koji je upravo sugerirao politiku promjene američkoga mentaliteta iz kulture potreba u kulturu želja, pri čemu je potrebno trenirati ljude da žele, da žude za novim stvarima, čak i prije nego što su stare stvari do kraja konzumirane. Ljudske želje moraju zasjeniti njihove objektivne potrebe. Želja je ta koja čini suvremenoga potrošača. Bili su to i počeci moderne, danas sveprisutne, marketinško-oglašivačke industrije u produkciji konzumerističkih znakova - logotipa, tržišno orijentiranih označitelja koncipiranih u svrhu stimulacije potrošačkih želja unutar suvremenih politika identiteta, koje su duboko određene suvremenim praksama korporativnih markiranja (Klein, 2002.). U desetljećima koja su uslijedila, logotipi i reklamne politike brendiranja nametnut će se kao jedni od ključnih mehanizama u produkciji konzumerističkih želja i kreiranju potrošačkih identiteta.

Sad već višestoljetni razvoj reklamne industrije doživio je niz mijena koje je moguće promatrati i iz perspektive uloge potrošačke kulture u oblikovanju i konstantnom transformiranju životnih stilova potrošača i njihovih identiteta. Na to ukazuje i Christopher Lash kada tvrdi da je "u jednostavnija vremena reklama tek svraćala pažnju na proizvod i hvalila njegove prednosti, no sad stvara vlastiti proizvod: vječno nezadovoljnoga, nespokojnog, tjeskobnog i dosadom mučenoga potrošača”, iz čega slijedi zaključak kako "reklamiranje ne služi toliko oglašavanju proizvoda koliko promicanju potrošnje kao načina života” (Lash, 1986.:82). Vrlo uporabna studija na temu promicanja kulture produkcije potrošačkih želja i ulozi marketinškoga oglašavanja pritom iz povijesne perspektive, jest i knjiga Land of Desire, Williama Leacha, koja kroz analizu američkoga korporativnog biznisa u periodu između 1890. i 1930. prati transformaciju američkoga društva u društvo preokupirano konzumerizmom. Ta je transformacija uključivala viziju potrošačke kulture kao sredstva za ostvarivanje sreće, artikulirajući u to vrijeme novu svjetonazorsku maksimu: imaš pravo željeti! Osnovna narativna nit Leachove studije bazirana je na tezi o korijenima i hegemonijskom usponu nove elite s početka 20. stoljeća u SAD-u, vođene načelima potrošačke kulture, tj. "bogaćenjem i potrošnjom kao sredstvima za ostvarivanje sreće, kultom novoga i demokratizacijom želje" (Leach, 1993.:3). James Norris u svojoj studiji ide još i korak dalje u povijesnoj analizi spomenutih fenomena. Norris se bavi razdobljem između 1865. i 1920., dajući prikaz časopisnih kampanja i oglašavanja sapuna, bicikala, satova, cigareta ili automobila, u kontekstu razvoja masovnoga tržišta. Temeljna teza, koju analizom niza konkretnih primjera autor pokušava dokazati, jest kako je nakana "uporabe oglašavanja uvesti nove produkte, homogenizirati ukuse i kreirati potražnju" (Norris, 1990.:50). Corleyev opsežni tekst posvećen analizi razvoja marketinga s ovu stranu oceana, u Velikoj Britaniji, u razdoblju 1914.-1960., pokazuje kako su se stvari u Europi po ovom pitanju ipak nešto drugačije odvijale. Naime, tek od druge polovice 50-ih godina 20. stoljeća primjetne su značajnije promjene u poslovnim politikama britanskih firmi, kako bi promociju potrošačke kulture povezale s izrazitijim praksama oglašavanja (Corley, 1987.). 


\section{Zaključak}

Na kraju se nameće prividno jednostavno pitanje: kako se uhvatiti u koštac, napraviti iskorak iz začaranoga kruga dinamike potrošačke želje ili žudnje u svijetu koji intenzivno promovira načela potrošačke kulture i na njima promovirane identitetske prakse? Mogući putokazi k potencijalnim odgovorima svakako nisu nimalo laki, već se, upravo suprotno, čine itekako etički zahtjevnim. Yves Zarka podsjeća nas kako se u tim nastojanjima uputno prisjetiti teza nekih klasičnih autora, poput Schopenhauerovoga načela negiranja žudnje, svojevrsnoga nihilizma ili u koncipiranju drugačije dinamike žudnje "koja više ne bi bila obilježena egoizmom, konkurencijom i suparništvom, nego... slogom, zajedništvom, velikodušnošću", za što "valja prije svega osmisliti promjenu naših načina bivanja” (Zarka, 2010.:24). No, poteškoća s pristupima i mogućim rješenjima ovoga tipa, koji ciljaju na etički osviještenu, racionalnu osobu s jasno izgrađenim svjetonazorskim, pa čak i ideološkim, načelima po pitanju konzumerizma i životnoga stila općenito, nalazi se u činjenici kako je simptom potrošačke žudnje redovito isprovociran simboličkim posredovanjem i stimulacijom znakova upakiranih u formi reklamno-marketinške propagande fenomen podsvjesno-iracionalnoga karaktera manifestiran na razini pojedinca. Ako se zadržimo u tom kontekstu, potom odgovore možemo potražiti u sferama psihoanalize i socijalne psihologije.

Međutim, s obzirom da je fenomene promicanja kulture potrošačke želje potrebno i uputno prije svega promišljati u društvenim, ekonomskim, političkim i kulturološkim kontekstima socijalnih struktura, koje su danas itekako određene konzumerističkim obolom, za kvalitetnu analizu spomenutih fenomena, koji se upisuju u naše individualne i kolektivne mikrosvakodnevice, i dalje su od presudnoga značaja analize strukturalnih razina, dakle makrosociološki i filozofijski uvidi. U uvodu rada zagovarali smo tezu oko koje danas gotovo da postoji opći konsenzus u raspravama na temu konzumerizma, kao ideologije svakodnevnoga života postmodernističkoga društva - naše bismo vrijeme mogli nazvati ne samo epohom neoliberalnoga, već i potrošačkoga kapitalizma. Ova teza, oko koje se zapravo problemski vrti cijela studija, u radu je eksplicirana i teorijski elaborirana iz nekoliko konceptualnih i disciplinarnih rakursa, s ciljem ukazivanja na finalni zaključak teksta. Do značajnijih promjena u trendovima promicanja kulture potrošačkih želja neće i ne može doći unutar sistemskoga i strukturalnoga okvira neoliberalizma. Radi se o neraskidivo povezanim fenomenima koji, u simboličkom smislu, funkcioniraju po principu Moebiusove trake ${ }^{11}$. Mogući iskorak iz "začaranoga kruga" potrošačke želje, potencijalno je ostvariv samo s onu stranu postojećega dominantno-hegemonijskoga modela neoliberalno-potrošačkoga kapitalizma.

11 Moebiusova traka (u obliku osmice ukrivljena traka na kojoj se nalaze i subjekt i objekt koji se nikada ne mogu susresti, na istom su mjestu, ali na suprotnim stranama koje stalnim promicanjem mijenjaju...), klasičan je primjer kojem često pribjegava teorijska psihoanaliza u epistemološkom problematiziranju esencijalne dihotomije subjekt - objekt. U primjeru Moebiusove trake na mjestu smo susreta subjekta i objekta, ali istovremeno i na točki nemogućnosti njihova stvarnoga susreta: subjekt neposredno "upada" u objekt, postaje objektom i obratno, objekt postaje subjektom. Distanca je time ukinuta. 


\section{Literatura:}

1. Baudrillard, J. (1970). La société de consommation. Paris: Le Point.

2. Bauman, Z. (2002). Society under Siege. Cambridge: Polity Press.

3. Bauman, Z. (2007). Consuming Life. Cambridge: Polity Press.

4. Beilharz, P., Ur. (2001). The Bauman Reader. Oxford: Blackwell Publishing.

5. Belk, R. W.; Ger, G., Askegaard, S. (2003). The Fire of Desire: A Multisited Inquiry into Consumer Passion. The Journal of Consumer Research, 30(3): 326-351.

6. Campbell, C. (1987). The Romantic Ethic and the Spirit of Modern Consumerism. Oxford: Basic Blackwell.

7. Cook, D. Th. (2005). Consumer Culture, u: Jacobs, Mark D. i Weiss, Hanrahan, Nancy (eds.). The Blackwell Companion to the Sociology of Culture. Oxford:Blackwell Publishing.

8. Cook, R. (2007). Good Bye Lenin!: Free Market Nostalgia for Socialist Consumerism. A Journal of Germanic Studies, 43 (2):206-219.

9. Corley, T. A. B. (1987). Consumer Marketing in Britain 1914-60. Business History, 29 (4):65-83.

10. Čolić, S. (2008). Sociokulturni aspekti potrošnje, potrošačke kulture i društva. Društvena istraživanja, 17 (6):953-973.

11. Debord, G. (1999). Društvo spektakla. Zagreb: Arkzin.

12. Duda, I. (2005). U potrazi za blagostanjem. Zagreb: Srednja Europa.

13. Foucault, M. (1994). Znanje i moć. Zagreb: Globus.

14. Freud, S. (1997). The Interpretation of dreams. London: Wordsworth Edition Limited.

15. Harvey, D. (2005). A Brief History of Neoliberalism. New York: Oxford University Press.

16. Hromadžić, H. (2008). Konzumerizam. Potreba, životni stil, ideologija. Zagreb: Jesenski i Turk.

17. Jureško, G. (2011). Neuromarketing: Autori reklama odlučili su provjeriti kada mozak šapće - kupi. Internetsko izdanje Jutarnjeg lista. Pregledano 22. 04. 2011. (http://www.jutarnji.hr/neuromarketing--autori-reklama-zakljucili-su-da-osimnjih-i-kupci-lazu--zato-su-odlucili-provjeriti-kada-mozak-sapce---kupi/931041/)

18. Kalanj, R. (2001). Postmodernistički vidokrug Jeana Baudrillarda, u: Baudrillard, J. Simulacija $i$ zbilja. Zagreb: Jesenski i Turk.

19. Klein, N. (2002). No Logo. Zagreb: V.B.Z.

20. Kullashi, M. (1986). Ka metafilozofiji/o lefebvreovu misaonom pothvatu. Zagreb: Biblioteka Filozofska misao.

21. Lacan, J. (2005). Ecrits: A selection. New York: W. W. Norton.

22. Lash, Ch. (1986). Narcistička kultura. Zagreb: Naprijed.

23. Leach, W. (1993). Land of Desire: Merchants, Power, and the Rise of a New American Culture. New York: Random House.

24. Lefebvre, A. (1988). Kritika svakidašnjeg života. Zagreb: Napredak.

25. Liechty, M. (2003). Suitably Modern: Making Middle-Class Culture in a New Consumer Society. Princeton N. J.: Princeton University Press.

26. Lowenthal, L. (1961). Literature, Polular Culture, and Society. Englewod Cliffs, NY: Prentice Hall. 
27. Matt, S. J. (2003). Keeping Up with the Joneses: Envy in American Consumer Culture, 1890-1930. Philadelphia: University of Pennsylvania Press.

28. Mesarić, M. (2006). Dugoročna neodrživost tržišnog fundamentalizma i neoliberalnog kapitalizma. Ekonomski pregled, 57 (9-10):603-630.

29. Mogilner, C., Rudnick, T., Iyengar, Sh. (2008). The Mere Categorization Effect: How the Presence of Categories Increases Choosers' Perceptions of Assortment Variety and Outcome Satisfaction. Journal of Consumer Research, 35 (2):202215.

30. Norris, J. (1990). Advertising and the Transformation of American Society, 18651920. Westport: Greenwood Press.

31. Oropesa, R. S. (1995). Consumer Possessions, Consumer Passions, and Subjective Well-Being. Sociological Forum, 10 (2):215-244.

32. Rhodes, Ch. (1994). "Writing up the New Negro": The Construction of Consumer Desire in the Twenties. Journal of American Studies, 28 (2):191-207.

33. Schultz, C. J. (1994). "Balancing Policy, Consumer Desire and Corporate Interests: Considerations for Market Entry in Vietnam". Columbia Journal of World Business, 94 (4):42-52.

34. Slater, D. (1997). Consumer Culture \& Modernity. Cambridge: Polity Press.

35. Stanić, S. (2010). Potrošnja u socijalizmu i tranziciji. Školski vjesnik, 59 (2):277293.

36. Stearns, P. (2001). Consumerism in World History - The Global Transformation of Desire. London: Routledge.

37. Velikonja, M. (2010). Titostalgija. Beograd: XX vek.

38. Zarka, Y. Ch. (2010). Kapitalizam, neobična privlačnost. Europski glasnik, XV (15): 21-24.

39. Žižek, S. (2008). O nasilju. Zagreb: Naklada Ljevak. 
Hajrudin Hromadžić

Filozofski fakultet u Rijeci, Odsjek za kulturalne studije, Rijeka, Hrvatska

e-mail: hhromadzic@ffri.hr

\title{
Consumer Capitalism: Era of the Manufacturing of Consumer Desire
}

\begin{abstract}
The article examines the character of consumer capitalism in the light of the manufacturing of consumer desire. The problem is not discussed as a mere socio-cultural phenomenon, but also an ideological one. As such, it is placed in a historical context - the beginning of the 1920s, first in the USA and later in the rest of the so-called western cultures. Aspects which turn out to be of crucial importance in an attempt to interpret consumer capitalism are psychoanalysis, the relationship between neo-capitalism and neo-liberalism, ideology of socialism and consumer culture as well as the role of marketing/ advertising machinery in the creation of consumer fantasies.
\end{abstract}

Key words: consumer capitalism, consumer desire, marketing, advertising. 